\title{
Interaction Between Acute Exercise and Carnitine Supplementation on the Expression of Genes Involved in Liver Metabolism in Male Rats
}

\author{
Beydolah Shahouzehi $^{1,2(\mathbb{D})}$, Soheil Aminizadeh ${ }^{3(\mathbb{D})}$, Yaser Masoumi-Ardakani ${ }^{3 *}$ (D) \\ 1 Student Research Committee, Kerman University of Medical Science, Kerman, Iran; bshahouzehi@gmail.com, \\ b.shahozehi@kmu.ac.ir (B.S.); \\ 2 Cardiovascular Research Center, Institute of Basic and Clinical Physiology Sciences, Kerman University of Medical \\ Sciences, Kerman, Iran \\ 3 Physiology Research Center, Institute of Neuropharmacology, Kerman University of Medical Sciences, Kerman, Iran; \\ soheilaminizadeh@gmail.com (S.A.); ymasoumi@kmu.ac.ir (Y.M.A.); \\ * Correspondence: ymasoumi@kmu.ac.ir (Y.M.A.);
}

Scopus Author ID 36617532100

Received: 22.06.2021; Revised: 26.07.2021; Accepted: 30.07.2021; Published: 15.08.2021

\begin{abstract}
Acute exercise induces rapid and dramatic induction of transcription in the liver. The beneficial effects of carnitine on serum factors and gene expression have been proven. This study examined the interaction between acute exercise and carnitine supplementation on the expression of genes involved in liver metabolism. Thirty-two male Wistar rats were randomly assigned into 4 groups $(\mathrm{n}=8)$ : Group 1 control, Group 2 received $200 \mathrm{mg} / \mathrm{kg} /$ day LCAR, Group 3 performed acute exercise, and Group 4 received LCAR and performed acute exercise. Gene expression in the liver was evaluated by Real-time PCR. Acute exercise significantly increased PDK4 expression compared to other groups. Also, carnitine administration, performing an acute exercise, and combination of LCAR-Acute significantly increased AMPK and PGC-1a expression compared with the control group. The expression of SREBP-1c and SCD1 was not significantly changed between studies. The combination of acute exercise and carnitine administration increased PGC-1a expression, indicating the importance of carnitine with exercise as a beneficial supplement.
\end{abstract}

Keywords: carnitine; exercise; real-time PCR; AMPK; PGC-1 $\alpha$; PDK4.

(C) 2021 by the authors. This article is an open-access article distributed under the terms and conditions of the Creative Commons Attribution (CC BY) license (https://creativecommons.org/licenses/by/4.0/).

\section{Introduction}

The capacity of a system to regulate the oxidation of energy sources based on the availability of these fuels is called metabolic flexibility. The ability to change the substrate consumption in response to the metabolic requirements depends on the balance between the oxidation of the fuel and the tissue's capacity to store it. In the meantime, competition between fatty acids and glucose for entry into metabolic oxidation pathways occurs at the level of pyruvate dehydrogenase complex (PDC) [1]. Sources of cellular fuel (carbohydrate and lipid) can compete and interact with oxidation $[1,2]$.

The PDC complex performs oxidative decarboxylation of pyruvate, linking the metabolism of fatty acids and carbohydrates [3]. PDC inactivation is catalyzed by the pyruvate dehydrogenase kinases (PDKs) [3]. PDK activity can be regulated by levels of metabolic intermediates such as pyruvate and transcription factors such as PGC- $1 \alpha$ under different conditions in different tissues [1, 4-6]. AMPK plays a vital role in maintaining energy balance 
in the cell [7-9]. Overall, AMPK activation increases PGC1 expression, and AMPK requires activity to modulate the expression of many key genes involved in mitochondrial and glucose metabolism [10-12]. Other genes involved in energy metabolism include SREBPs, PPARs, SCD1, and MCAD [13]. The enzyme MCAD plays an important role in the oxidation of lipids.

The main role of carnitine (beta-hydroxy-gamma trimethyl ammonium butyrate) in the body is to facilitate the oxidation of long-chain fatty acids by transferring them into the mitochondrial $[14,15]$. Therefore, without carnitine, most dietary lipids cannot be used and accumulate in the body, eventually leading to obesity. Carnitine is absorbed in the intestine through sodium-dependent active transport and inactive transport [14, 15]. Carnitine is considered a worldwide supplement, and its most important effects are weight loss and fat mass reduction (so-called fat burning) [14-16].

It was shown that people who took carnitine supplements and exercised improved lipid profile, oxidative muscle capacity, and higher athletic performance [2, 16-18]. Additionally, it was reported that carnitine supplementation ameliorated muscle damage [19]. Exercise leads to an increase in PGC-1 $\alpha$ expression that affects a wide range of cellular functions $[4,5,20]$. It was described that exercise training affects PDK4 levels [1]. Exercise reduced hepatic PPAR $\gamma$ expression and downstream targets such as SREBP-1c, ACC1, SCD-1, and fatty acid synthase (FAS). Pala et al. (2018) showed that acute exercise could affect MDA levels and reduce the expression of glucotransporters and PPAR-gamma in the liver and muscle [21].

Broderick et al. also investigated the effect of acute exercise on the expression of genes involved in fat metabolism and showed that the expression of PGC-1a and CPT1 genes was increased after exercise [22]. L-carnitine supplementation with regular aerobic exercise improves liver tissue apoptosis in type 2 diabetic subjects [23]. The beneficial effects of an exercise session have been demonstrated in some studies. For example, Taybi et al. showed that an exercise session increased hepatic ABCA1 expression [24].

Acute exercise induces rapid and dramatic induction of transcription in the liver. Huen et al. showed that acute exercise increased the expression of PDK4, PGC-1a, AMPK, and IRS2 genes in the liver, while FAS expression decreased and CPT $1 \alpha$ expression remained unchanged [25]. Also, another study showed that an acute exercise session increased serum FGF21 levels in mice and healthy males. In addition, they found that FGF21 expression was increased in the liver but not in the white adipose tissue and skeletal muscle of mice with acute exercise. Hepatic enhancement was associated with increased hepatic PPAR $\alpha$ expression [26].

The beneficial effects of carnitine on serum factors and gene expression have been proven, and even in some pathological conditions in animal models have had significant and beneficial effects. The body's metabolic system as a coordinated and integrated system is actually a function of changes caused by exercise and the use of carnitine supplements. Given these cases, the association between metabolic integration, carnitine supplementation, and exercise needs further investigation.

One of the reasons is the limited number of studies on the effects of carnitine supplementation. Most previous studies have investigated anthropometric alterations, insulin sensitivity, and decreased fat mass. On the other hand, there was a lack of a more detailed study on the effects of carnitine administration as well as the simultaneous effect of carnitine supplementation and acute exercise on the expression of genes involved in metabolism. We designed this study to determine the interaction between performing acute exercise and Lcarnitine intraperitoneal administration on the expression of PDK4, AMPK, MCAD, CS, SREBP1, SCD1, and PGC-1 $\alpha$ genes in the liver of male Wistar rats. 


\section{Materials and Methods}

\subsection{Materials.}

The materials that used in this study were including; L-carnitine (Sigma, L-Carnitine hydrochloride, Cat number: C0283), Total RNA extraction kit (BioBasic, EZ-10 Spin Column Total RNA Miniprep Kit, Cat number: BS82312), cDNA synthesis kit (TAKARA, Prime Script RT Reagent Kit, Cat number: RR037A), 2X SYBR Green (Ampliqon, Cat number: A325402), and primers (purchased from Metabion, Germany).

\subsection{Methods.}

All animal care and procedures were conducted according to the European Convention for the protection of animals used for experimental and other scientific purposes. This study was approved by the ethics committee of Kerman University of Medical Sciences with number, IR.KMU.REC.1399.536.

\subsection{Animals.}

Thirty-two male Wistar rats in the age range of 8 weeks were purchased from the pet center of Kerman Physiology Research Center and kept in the laboratory with a temperature of $22 \pm 2^{\circ} \mathrm{C}$ and a light-dark cycle of $12 / 12$ hours. Animals will have free access to water and food. Rats will first be tested for two weeks to familiarize themselves with the laboratory environment. After acclimatization, the animals were randomly assigned into 4 groups $(n=8)$ as follow; Group 1 control which did not receive carnitine, Group 2 received $200 \mathrm{mg} / \mathrm{kg} / \mathrm{day}$ LCAR by i.p. injections ( 4 weeks), Group 3 acute exercise group, and Group 4 that received $200 \mathrm{mg} / \mathrm{kg} /$ day LCAR and performed acute exercise.

\subsection{Exercise protocol.}

The acute exercise was performed in one session in the relevant groups 12 hours before killing the animals. Thus, the animals on the treadmill start at a speed of 10 meters per second and slowly increase to a speed of 30 meters per second. The duration of the exercise was 45 minutes [24-26].

\subsection{Total RNA extraction, cDNA synthesis, and real-time PCR.}

The liver tissue was used for total RNA extraction. Twenty milligrams of liver tissue were dissected and homogenized using lysis buffer supplied in the kit by Hielscher Sonicator (Hielscher H200, Germany). The obtained homogenate was loaded into the EZ-10 spin column, and RNAs were isolated according to the kit instructions. Then, isolated RNA quality and quantity were determined by the Nano-drop instrument. Finally, we used $500 \mathrm{ng}$ of total extracted RNA in order to synthesize cDNA that was performed by Parstous cDNA synthesis kit according to the kit instructions [24-26].

We used ABI Step one plus instrument to perform Real-time PCR reactions. Each reaction mixture was contained $10 \mu \mathrm{l}$ SYBR green, $100 \mathrm{ng}$ of synthesized cDNA, primers (forward $\&$ reverse primers; $1 \mu 1$ from each primer), and the reaction volume was reached to 20 $\mu l$ by distilled water. We used primer's Tm to determine the annealing temperature and then performed gradient PCR using Bio-Rad thermocycler. The thermal protocol in real-time PCR 
was as follows: 95 (10 min), 95 (20 sec), annealing temperature (45 sec), 40 cycles, and after the thermal cycles were finished, the melt curve analysis was performed. In the current study, $18 \mathrm{~S}$ rRNA was used as the housekeeping gene. The relative expression of genes was determined by $2^{-\Delta \Delta C t}$ method [24-26]. Gene-specific primers were used to perform Real-time PCR measurements (Table 1).

Table 1. The primers sequences that used in this study in order to perform real-time PCR.

\begin{tabular}{l|l|l} 
Gene & Forward & Reverse \\
\hline AMPK & TTAAACCCACAGAAATCCAAACAC & CTTCGCACACGCAAATAATAG \\
\hline CS & CGGTTCTTGATCCTGATGAGGG & ACTGTTGAGGGCTGTGATGGC \\
\hline MCAD & CGCCCCAGACTACGATAAAA & CAAGACCACCACAACTCTCC \\
\hline PDK4 & AAGCCCTGATGGACACCTC & GAAGCCTGGGATGCTCTTG \\
\hline Srebp-1c & GACGACGGAGCCATGGATT & GGGAAGTCACTGTCTTGGTTGTT \\
\hline SCD1 & AAAGTTTCTAAGGCCGCTG & GTCTGAGCCAGCAATCTCAA \\
\hline PGC-1 $\alpha$ & ACCCACAGGATCAGAACAAACC & GACAAATGCTCTTTGCTTTATTGC \\
\hline $18 S$ & GCAATTATTCCCCATGAACG & GGCCTCACTAAACCATCCAA
\end{tabular}

\subsection{Statistical analysis.}

Data analysis was performed using SPSS software (Version 20). One-way analysis of variance (ANOVA) was used to determine the differences in variables between groups along with Tukey's HSD post-hoc test. In all statistical comparisons, a significance level of $\mathrm{P}<0.05$ was considered significant.

\section{Results and discussion}

Acute exercise significantly increased PDK4 expression compared to other groups ( $\mathrm{p}$ values; vs control $p=0.011$, vs LCAR and combination of LCAR-Acute $p<0.001$ ) (Figure 1).

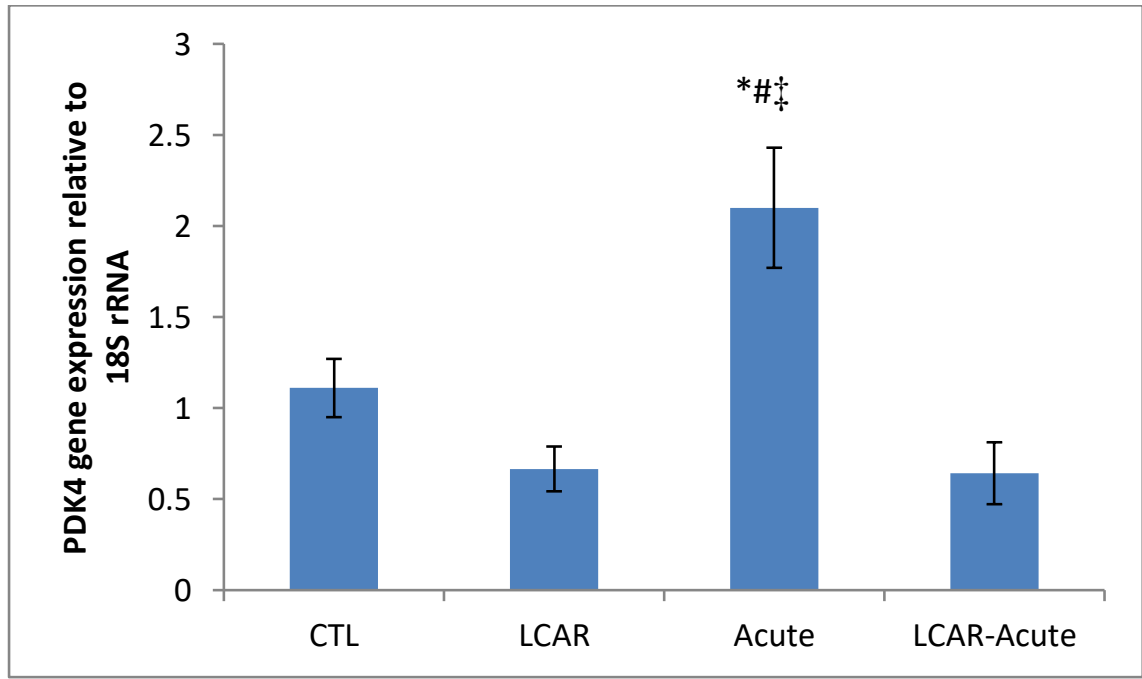

Figure 1. PDK4 gene relative expression in 4 studied groups, including control (CTL), received L-carnitine (LCAR), performed acute exercise, and LCAR-Acute. Data are expressed as Mean SEM, p < 0.05 was considered as a significant difference. * statistically significant compared to control group, \# statistically significant compared to LCAR group, $\$$ statistically significant compared to LCAR-Acute group. 


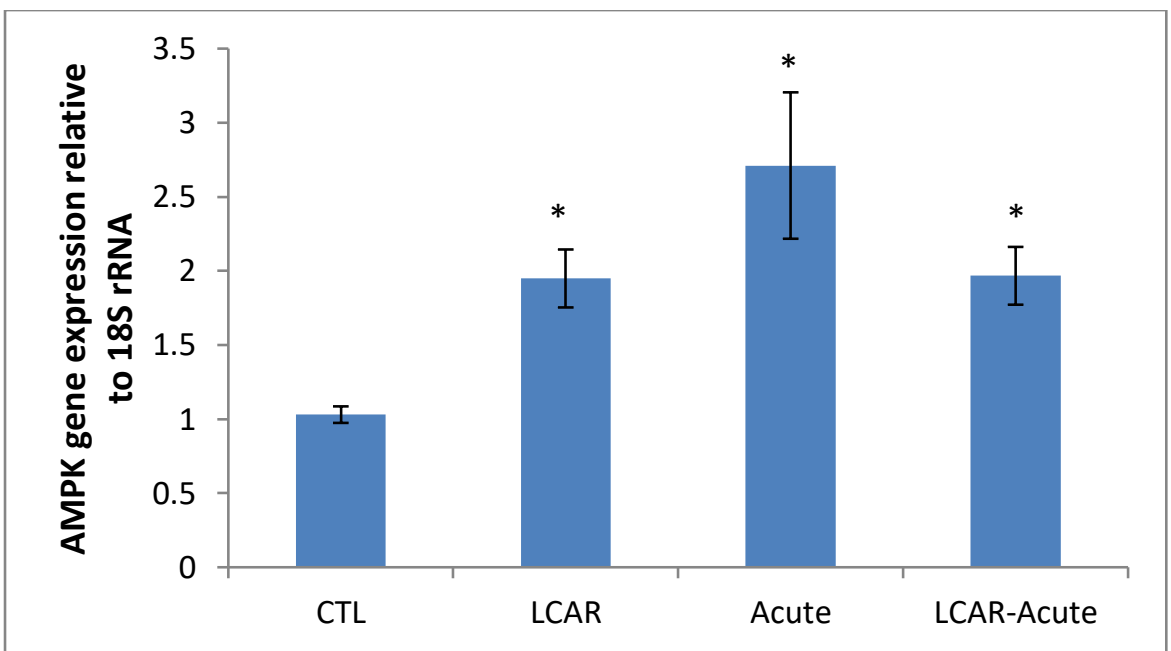

Figure 2. AMPK gene relative expression in 4 studied groups, including control (CTL), received L-carnitine (LCAR), performed acute exercise, and LCAR-Acute. Data are expressed as Mean SEM, p $<0.05$ was considered as a significant difference. * statistically significant compared to the control group.

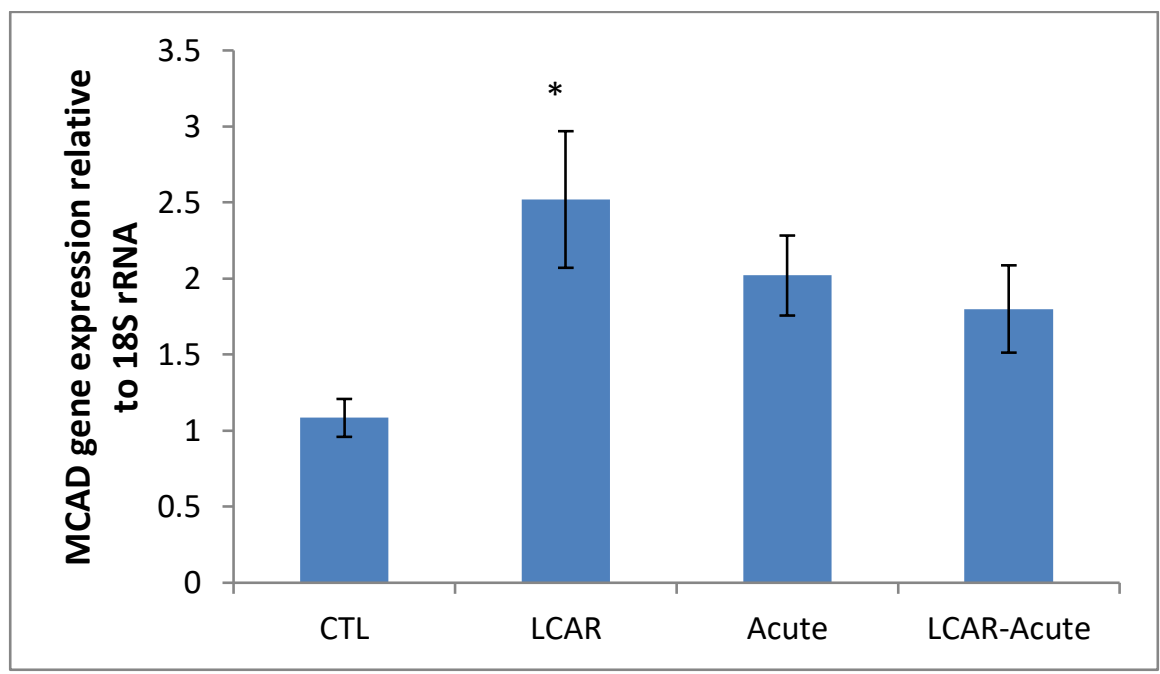

Figure 3. MCAD gene relative expression in 4 studied groups, including control (CTL), received L-carnitine (LCAR), performed acute exercise, and LCAR-Acute. Data are expressed as Mean SEM, p $<0.05$ was considered as a significant difference. ${ }^{*}$ statistically significant compared to the control group.



Figure 4. CS gene relative expression in 4 studied groups, including control (CTL), received L-carnitine (LCAR), performed acute exercise, and LCAR-Acute. Data are expressed as Mean SEM, $p<0.05$ was considered as a significant difference. \# statistically significant compared to LCAR group. 


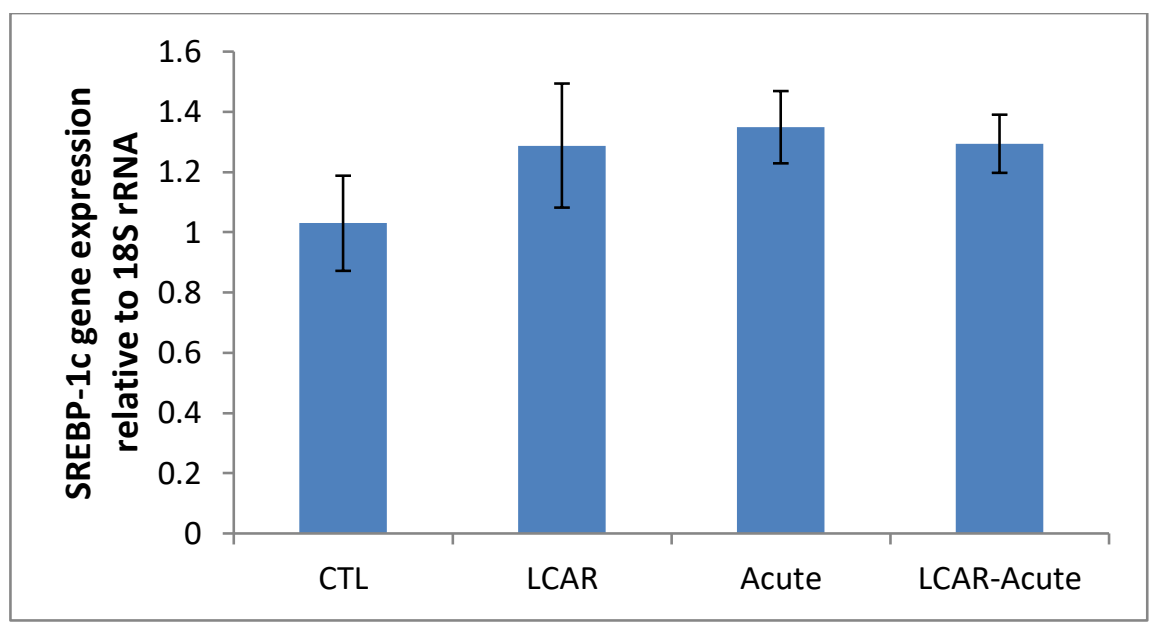

Figure 5. SREBP-1c gene relative expression in 4 studied groups, including control (CTL), received L-carnitine (LCAR), performed acute exercise, and LCAR-Acute. Data are expressed as Mean SEM, $\mathrm{p}<0.05$ was considered as a significant difference.

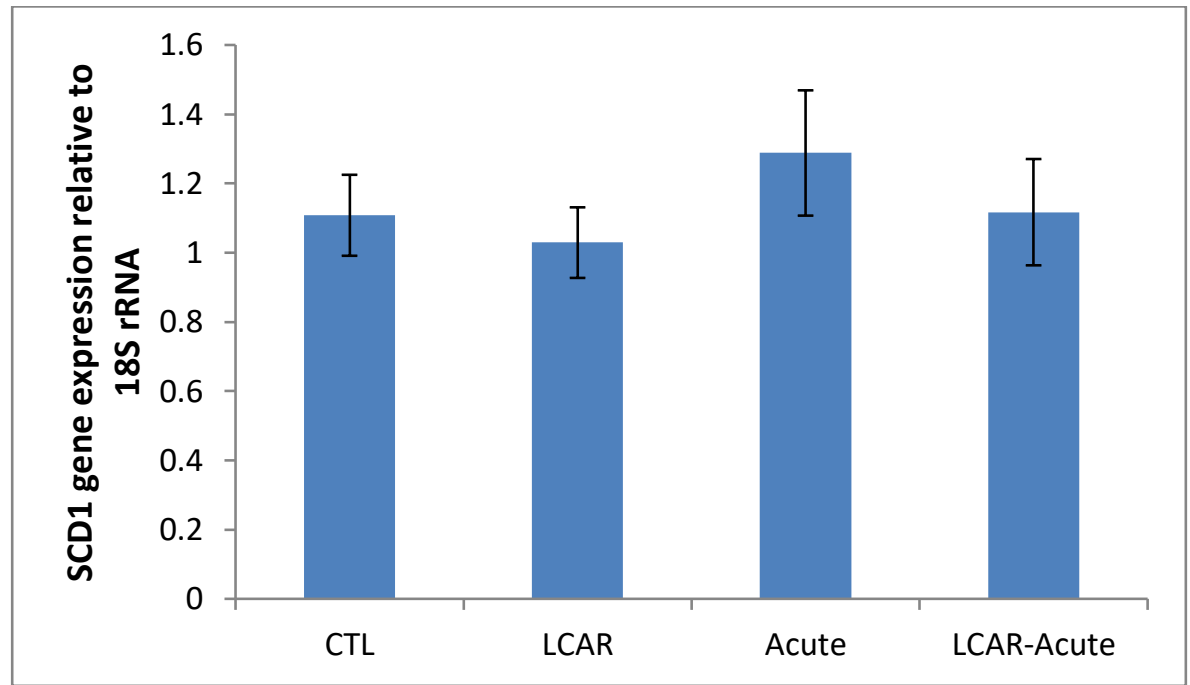

Figure 6. SCD-1 gene relative expression in 4 studied groups, including control (CTL), received L-carnitine (LCAR), performed acute exercise, and LCAR-Acute. Data are expressed as Mean SEM, p < 0.05 was considered as a significant difference.

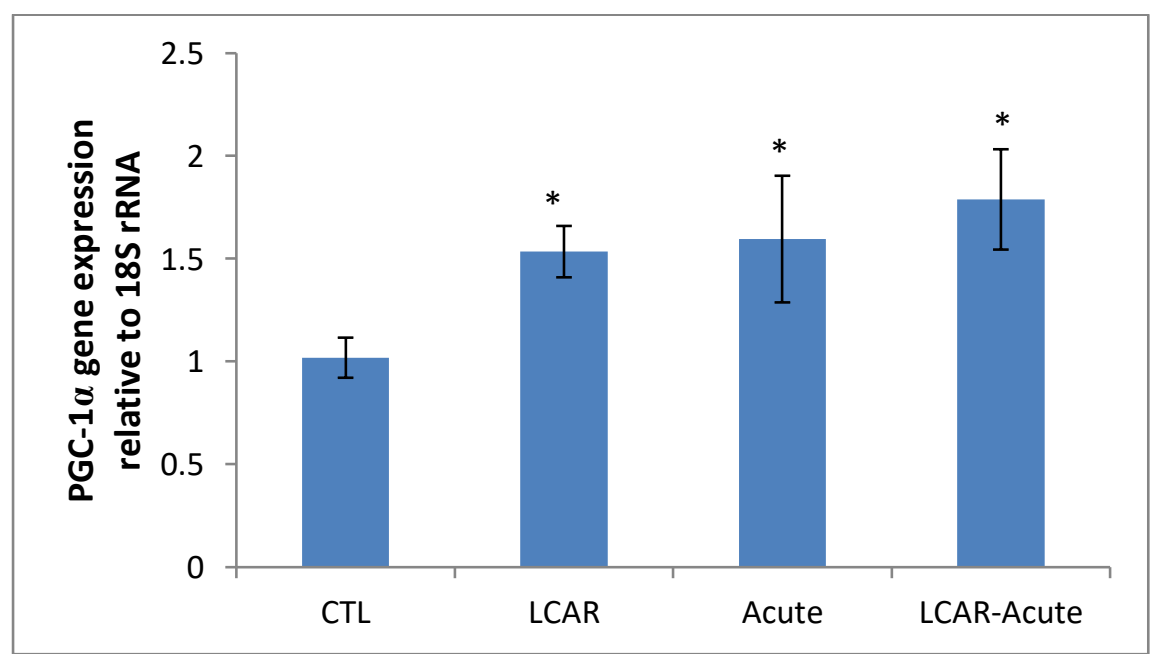

Figure 7. PGC-1 $\alpha$ gene relative expression in 4 studied groups, including control (CTL), received L-carnitine (LCAR), performed acute exercise, and LCAR-Acute. Data are expressed as Mean SEM, p < 0.05 was considered as a significant difference.* statistically significant compared to the control group. 
Compared with the control group, carnitine administration, performing the acute exercise, and combination of LCAR-Acute significantly increased AMPK and PGC-1 $\alpha$ expression (Figures 2 and 7). MCAD level was significantly higher in the group that received carnitine $(\mathrm{p}=0.026)$ (Figure 3$)$, and CS expression was upregulated by exercise $(\mathrm{p}=0.012)$ (Figure 4). The expression of SREBP-1c and SCD1 was not significantly changed between the studied groups (Figures 5 and 6).

Acute exercise induces rapid and dramatic induction of transcription in the liver. Carnitine supplementation's beneficial effects were reported previously [2-6, 16-19, 25, 26]. In the current study, we have evaluated the interaction between carnitine supplementation (200 $\mathrm{mg} / \mathrm{kg} / \mathrm{d}$, i.p) and acute exercise on the expression of genes involved in liver metabolism. Acute exercise increased PDK4 expression. PDK4 inhibits pyruvate oxidation in mitochondria by inhibiting PDC activity and increasing the conversion of pyruvate to lactate. The study by Huen et al. showed that acute exercise increased the expression of PDK4 in the liver [25], which is consistent with the results of our study. However, in the group that combined acute exercise with carnitine intake (group 4), carnitine administration neutralized the effect of acute exercise on PDK4 expression. By decreasing PDK4, carnitine appears to cause the pyruvate pathway to flow through the PDC, increase acetyl CoA, and increase the Krebs cycle [2].

AMPK activates catabolic pathways and inhibits anabolic pathways. It was documented that exercise training increases AMPK expression and activity [7, 8]. Pataky et al. (2020) have shown that AMPK-gamma was upregulated 3 hours after exercise training [10]. It was described previously that carnitine supplementation increases AMPK expression in the liver, which is consistent with our present results [27]. Acute exercise has also increased AMPK expression, which is in line with the study of Huen et al. [25]. During exercise, the AMP / ATP ratio increases and therefore increases and activates AMPK, which ultimately leads to increased glycolysis and glucose oxidation pathway activity [7, 8]. In the present study, the animals performed acute exercise, and due to acute exercise, there was an urgent need for energy, and therefore the body prefers pyruvate to produce lactate and obtain ATP faster.

MCAD is essential for the oxidation of fatty acids by the beta-oxidation pathway. Additionally, carnitine has been shown to increase MCAD expression due to its fat-burning properties through transferring fatty acids into the mitochondria matrix [28]. However, acute exercise and the combination of acute exercise and carnitine did not significantly alter MCAD expression. Given the need to oxidize carbohydrates relative to lipids, this is not unexpected during acute exercise. But the important point here is that acute exercise has been able to eliminate the effect of carnitine on MCAD expression. The lipogenic genes expression was not changed significantly in the current study. Neither carnitine supplementation nor acute exercise was able to later SREBP-1c and SCD1 expression in the liver.

PGC-1 $\alpha$, which plays an important role in mitochondrial biogenesis, was significantly increased in all three studied groups compared to controls. In previous studies, such as the study of Huen et al. and the study of Broderick et al., acute exercise has been shown to increase PGC-1 $\alpha$ expression, which is similar to the finding in our study [22, 25]. Also, Park and colleagues (2020) reported that acute exercise increased PGC-1 $\alpha$ expression [5]. PGC-1 $\alpha$ plays an important role in mitochondrial respiration, antioxidant defense, and lipid and carbohydrate metabolism, and therefore, acute exercise can exert some beneficial effects through the upregulation of PGC- $1 \alpha$. 


\section{Conclusions}

The combination of acute exercise and carnitine administration increased PGC- $1 \alpha$ and AMPK expression, indicating the importance of carnitine with exercise as a beneficial supplement. But, it is necessary to evaluate the protein level and activity of these factors in this model to find out more precisely about the adaptation which results from acute exercise in animal models.

\section{Funding}

This research received no external funding.

\section{Acknowledgments}

The present article was financially supported by the Kerman Medical University Research Council.

\section{Conflict of interest}

The authors declare no conflict of interest.

\section{References}

1. Zhang, S.; Hulver, M.W.; McMillan, R.P.; Cline, M.A.; Gilbert, E.R. The pivotal role of pyruvate dehydrogenase kinases in metabolic flexibility. Nut Metab (Lond) 2014, 11, 1-10, https://doi.org/10.1186/1743-7075-11-10.

2. Koozehchian, M.S.; Daneshfar, A.; Fallah, E.; Agha-Alinejad, H.; Samadi, M.; Kaviani, M.; Kaveh, M.; Jung, Y.P.; Hassanzadeh Sablouei, M.; Moradi, N.; Earnest, C.P.; Chandler, T.J.; Kreider, R.B. Effects of nine weeks L-Carnitine supplementation on exercise performance, anaerobic power, and exercise-induced oxidative stress in resistance-trained males. $J$ Exerc Nutrition Biochem 2018, 22, 7-19, https://doi.org/10.20463/jenb.2018.0026.

3. Jeoung, N.H. Pyruvate Dehydrogenase Kinases: Therapeutic Targets for Diabetes and Cancers. Diabetes Metab J. 2015, 39, 188-197, https://doi.org/10.4093/dmj.2015.39.3.188.

4. Larson, C.; Opichka, M.; McGlynn, M.L.; Collins, C.W.; Slivka, D. Exercise- and Cold-Induced Human PGC-1 $\alpha$ mRNA Isoform Specific Responses. Int. J. Environ. Res. Public Health 2020, 17, 5740, https://doi.org/10.3390/ijerph17165740.

5. Park, J.S.; Holloszy, J.O.; Kimm K.; Koh, J.H. Exercise Training-Induced PPAR $\beta$ Increases PGC-1 $\alpha$ Protein Stability and Improves Insulin-Induced Glucose Uptake in Rodent Muscles. Nutrients 2020, 12, 652, https://doi.org/10.3390/nu12030652.

6. Rius-Pérez, S.; Torres-Cuevas, I.; Millán, I.; Ortega, A.L.; Pérez S. PGC-1 $\alpha$, Inflammation, and Oxidative Stress: An Integrative View in Metabolism. Oxid. Med. Cell. Longev. 2020, https://doi.org/10.1155/2020/1452696.

7. Pataky, M.W.; Arias, E.B.; Wang, H.; Zheng, X.; Cartee, G.D. Exercise effects on 3-AMPK activity, phosphorylation of Akt2 and AS160, and insulin-stimulated glucose uptake in insulin-resistant rat skeletal muscle. J Appl Physiol 2020, 128, 410-421, https://doi.org/10.1152/japplphysiol.00428.2019.

8. Machrina, Y.; Pane, Y.S.; Lindarto, D. The Expression of Liver Metabolic Enzymes AMPKa1, AMPK $\alpha 2$, and PGC-1 $\alpha$ due to Exercise in Type-2 Diabetes Mellitus Rat Model. Maced J Med Sci [Internet] 2020, 8, 629-632, https://oamjms.eu/index.php/mjms/article/view/4550.

9. Vieira, R.F.L.; Junqueira, R.L.; Gaspar, R.C.; Muñoz, V.R.; Pauli, J.R. Exercise activates AMPK signaling: impact on glucose uptake in the skeletal muscle in aging. J Rehab Therapy 2020, 2, 48-53.

10. McConell, G.K.; Wadley, G.D.; Le plastrier, K.; Linden, K.C. Skeletal muscle AMPK is not activated during $2 \mathrm{~h}$ of moderate intensity exercise at $65 \% \mathrm{~V}^{\cdot}$ O2peak in endurance trained men. $J$ Physiol 2020, 598,18, 3859-3870, https://doi.org/10.1113/JP280447. 
11. Fontecha-Barriuso, M.; Martin-Sanchez, D.; Martinez-Moreno, J.M.; Monsalve, M.; Mario Ramos, A.; Sanchez-Niño, M.D.; Ruiz-Ortega, M.; Ortiz, A.; Belen Sanz, A. The Role of PGC-1 aand Mitochondrial Biogenesis inKidney Diseases. Biomolecules 2020, 10, 347, https://doi.org/10.3390/biom10020347.

12. Canto, C.; Auwerx, J. PGC-1a, SIRT1 and AMPK, an energy sensing network that controls energy expenditure. Curr Opin Lipidol 2009, 20, 98-105, https://doi.org/10.1097/MOL.0b013e328328d0a4.

13. Zhang, Q.; Xu, L.; Xia, J.; Wang, D.; Qian, M.; Ding, S. Treatment of diabetic mice with a combination of diet and aerobic exercise via modulations of PPARs gene programs. PPAR Research 2018, Article ID 4827643, https://doi.org/10.1155/2018/4827643.

14. Cha, Y.S. Effects of L-carnitine on obesity, diabetes, and as an ergogenic aid. Asian Pac J Clinnutr. 2008, 17, 306-308.

15. Sawicka, A.K.; Renzi, G.; Olek, R.A. The bright and the dark sides of L-carnitine supplementation: a systematic review. J Int Soc Sports Nut 2020, 17, 49, https://doi.org/10.1186/s12970-020-00377-2.

16. Yano, J.; Kaida, Y.; Maeda, T.; Hashida, R.; Tonan, T.; Nagata, S.; Hazama, T.; Nakayama, Y.; Ito, S.; Kurokawa, Y.; Otome, T.; Shibata, R.; Tashiro, K.; Kakuma, T.; Matsuse, H.; Fukami K. 1-carnitine supplementation vs cycle ergometer exercise for physical activity and muscle status in hemodialysis patients: A randomized clinical trial. Ther Apher Dial 2021, 25, 304-313, https://doi.org/10.1111/1744-9987.13576.

17. Varney, J.L.; Fowler, J.W.; McClaughry, T.C.; Vignale, K.; Caldas, J.; Weil, J.T.; Coon, C.N. L-Carnitine metabolism, protein turnover and energy expenditure in supplemented and exercised Labrador Retrievers. $J$ Anim Physiol Anim Nutr 2020, 104, 1540-1550, https://doi.org/10.1111/jpn.13391.

18. Karlic, H.; Lohninger, A. Supplementation of 1-carnitine in athletes: does it make sense? Nutrition 2004, 20,7 8, 709-715, https://doi.org/10.1016/j.nut.2004.04.003.

19. Yarizadh, H.; Shab-Bidar, S.; Zamani, B.; Vanani, A.N.; Baharlooi, H.; Djafarian, K. The Effect of L-Carnitine Supplementation on Exercise-Induced Muscle Damage: A Systematic Review and Meta-Analysis of Randomized Clinical Trials. J Am Coll Nutr 2020, 39, 457-468, https://doi.org/10.1080/07315724.2019.1661804.

20. Léveillé, M.; Besse-Patin, A.; Jouvet, N.; Gunes, A.; Sczelecki, S.; Jeromson, S.; Khan, N.P.; Baldwin, C.; Dumouchel, A.; Correia, J.C.; Jannig, P.R.; Boulais, J.; Ruas, J.L.; Estall, J.L. PGC-1 $\alpha$ isoforms coordinate to balance hepatic metabolism and apoptosis in inflammatory environments. Molecular Metabolism 2020, $34,72-$ 84, https://doi.org/10.1016/j.molmet.2020.01.004

21. Pala, R.; Genc, E.; Tuzcu, M.; Orhan, C.; Sahin, N.; Er, B. L-Carnitine supplementation increases expression of PPAR- $\gamma$ and glucose transporters in skeletal muscle of chronically and acutely exercised rats. Cellular and Molecular Biology 2018, 64, 1-6, DOI:10.14715/cmb/2018.64.1.1.

22. Broderick, T.L.; Cusimano, F.A.; Carlson, C.; Tamura, L.K. Acute Exercise Stimulates Carnitine Biosynthesis and OCTN2 Expression in Mouse Kidney. Kidney Blood Press Res 2017, 42, 398-405, https://doi.org/10.1159/000478737.

23. Jabbari, S.E.; Gholami, M.; Nikbakht, H.; Shakeri, N.; Ghazalian, F. Effect of aerobic training and L-carnitine supplementation on some apoptotic factors in diabetic rat liver. Razi J Med Sci. 2019, 26, 131-140, URL: http://rjms.iums.ac.ir/article-1-5798-en.html.

24. Tayebi, S.M.; Khademosharie, M.; Amiri Parsa, T.; Abaszadegan, M.; Saeidi, A.; Nenasheva, A.V. The Acute Effect Of Running Exercise On Liver Abca1 Gene Expression In Male Wistar Rats. Human Sport Medicine 2019, 19, 43-49, https://doi.org/10.14529/hsm19s106.

25. Hoene, M.; Lehmann, R.; Hennings, A.M.; Pohi, A.K.; Haring, H.U.; Schleicher, E.D.; Weiger, C. Acute regulation of metabolic genes and insulin receptor substrates in the liver of mice by one single bout of treadmill exercise. J Physiol 2009, 587, 241-252, doi:10.1113/jphysiol.2008.160275.

26. Kim, K.H.; Kim, S.H.; Min, Y.K.; Yang, H.M.; Lee, J.B.; Lee, M.S. Acute Exercise Induces FGF21 Expression in Mice and in Healthy Humans. PLoS ONE 2013, 8, e63517, https://doi.org/10.1371/journal.pone.0063517.

27. Shahouzehi, B.; Barkhordari, K.; Aminizadeh, S.; Masoumi-Ardakani, Y. Effect of L-carnitine administration on serum insulin and adiponectin levels, and AMPK, APPL1 and PPAR $\gamma$ gene expression in STZ-induced diabetic rat liver. Ukr.Biochem.J 2017, 89, 6, 48-55, doi:https://doi.org/10.15407/ubj89.06.048.

28. Marefati, H.; Masoumi-Ardakani, Y.; Shakerian, S.; Aminizadeh, S.; Shahouzehi, B. The Effects of Pyruvate Dehydrogenase Kinase 4 (PDK4) Inhibition on Metabolic Flexibility during Endurance Training in Skeletal Muscles of Streptozotocin-induced Diabetic Rats. Journal of Kerman University of Medical Sciences 2020, 27, 304-317, https://doi.org/10.22062/jkmu.2020.91017. 